\title{
Low Velocity Ballistic Behavior of Continuous Filament Knit Aramid
}

\author{
Ajmer K. Dwivedi ${ }^{1}$, Michael W. Dalzell ${ }^{2}$, Stephen A. Fossey ${ }^{3}$, Kyle A. Slusarski ${ }^{1}$, Larry R. \\ Long $^{1}$, and Eric D. Wetzel ${ }^{1}$ * \\ ${ }^{1}$ U.S. Army Research Laboratory \\ Aberdeen Proving Ground, MD 21005 \\ *eric.d.wetzel2.civ@mail.mil, 410-306-0851 \\ ${ }^{2}$ Defence Science and Technology Laboratory, Wiltshire, UK SP4 0JQ \\ ${ }^{3}$ U.S. Natick Soldier Research, Design, and Engineering Center \\ Natick, MA 01760
}

For submission to the International Journal of Impact Engineering

12 February 2016

Revision: 28 April 2016

\begin{abstract}
The ballistic perforation response of knits formed from continuous filament aramid is reported and compared to conventional armor textiles and commodity fabrics. The ballistic experiments consist of 6.0-mm-diameter glass spheres impacted into gelatin-backed targets with areal densities from $200-1000 \mathrm{~g} / \mathrm{m}^{2}$. These ballistic experiments are complemented with quasistatic reverse-perforation experiments to gain insights into deformation and failure for these materials. In-plane stretch experiments are also performed to quantify modulus and strain-tofailure. The results show that, while the ballistic performance of traditional woven textiles is generally superior to knitted aramids, knits formed from continuous filament aramid are significantly better than knits formed from staple yarn. Knitted structures are limited by two main factors: failure of a single yarn tends to lead to catastrophic deconstruction and perforation, and the low in-plane modulus of knits leads to poor lateral stress transfer and energy distribution during higher speed impact. Importantly, however, knits provide significantly more reversible
\end{abstract}


elongation with less elastic resistance compared to other structures, such as woven textiles, making them well-suited for wearable protection in which comfort is critical. The results also show that continuous filament knits can be produced with commercial manufacturing equipment, and that barriers composed of few layers of high-denier yarn knits likely provide more efficient ballistic resistance than equivalent weight barriers composed of many layers of low-denier yarn knits.

\section{Introduction}

The majority of ballistic textiles research focuses on woven fabrics, the most common

4 architecture used in ballistic barriers such as body armor [1,2]. The woven structure of these

5 textiles are well-suited for ballistics for a number of reasons including: low-crimp woven yarns

6 are relatively straight, and therefore load during ballistic impact without significant backface

7 deformation; yarns can be closely packed, limiting lateral yarn motion during ballistic loading;

8 and, for typical woven architectures and projectile geometries, projectile loads can be shared

9 amongst multiple yarns simultaneously, so that multiple yarns must be failed in order for a

10 projectile to penetrate a woven fabric barrier.

11 Woven fabrics are not stretchable along their principal axes [3]. For many ballistic

12 barriers, such as torso body armor or turbine blade containment systems, stretch is not a primary

13 requirement. However, for some applications it is beneficial to have an armor material that is

14 stretchable, for example for close-fitting protective garments, ballistic shorts, and extremity

15 armor. Stretchable textiles enable greater freedom of motion, and therefore comfort, than

16 comparable woven textiles. 
Dwivdei et. al, "Low Velocity Ballistic Behavior... Knit Aramid"

Knits are a textile architecture with inherently high stretch, due to the looped

18 configuration of the comprising yarns (Fig. 1) [4, 5]. The two principal axes of the knit structure

19 are referred to as courses (side-by-side series of loops) and wales (interlocked head-to-tail series

20 of loops). The simplest and most common structure is a single jersey knit, in which each course

21 is composed of a single yarn. Although the quasistatic mechanics of knits have been the topic of

22 considerable experimental $[6,7]$ and theoretical $[8,9]$ investigation, as well as limited

23 computational simulation [10,11], little systematic data on the ballistic performance of knits has

24 been reported. One early study on unbacked, edge-clamped nylon knits, using lead pellets fired

25 at an impact energy of $9.4 \mathrm{~J}$ and target areal densities of $80-120 \mathrm{~g} / \mathrm{m}^{2}(\mathrm{gsm})$, found that the knit

26 ballistic performance was only slightly below that of a comparable plain-woven nylon textile

27 [12]. A subsequent study [13] compared woven and knit Kevlar textiles, impacted with steel

28 cylindrical projectiles at higher energies (125 J) and areal densities (1000-5000 gsm), and found

29 that the knits required more mass (approximately $2.5 \times$ ) to achieve the same ballistic performance

30 level as a woven textile. Studies on knitted high performance yarns, at lighter areal densities

31 (200-1000 gsm) appropriate for extremity armors or other close-fitting protective garments, have

32 not been reported. Some research has indicated that knitting high performance yarns could lead

33 to degradation in yarn tensile properties during the knitting process [14], which could limit

34 barrier performance.

35 In this study, the ballistic behavior of continuous filament, knitted aramids (CFKAs) is

36 compared with conventional armor textiles and commodity fabrics. CFKA materials include

37 knits created using a commercial knitting loom, allowing for a systematic comparison of

38 architecture parameters while demonstrating the manufacturability of continuous filament knits.

39 Commodity fabrics include knitted staple yarn aramids, in which the yarns are composed of 
40 short, entangled filaments, in contrast to the continuous filaments of the CFKA material.

41 Elongation experiments are performed to characterize in-plane elastic modulus and strain-to-

42 failure for a subset of the textiles, and quasistatic reverse perforation experiments provide

43 additional insights into the mechanistic progression of failure in knits compared to other

44 materials.

2. Experimental

\section{$47 \quad 2.1$ Materials}

\section{$48 \quad 2.1 .1$ Baseline materials}

Table 1 lists all of the baseline materials evaluated. Baseline fabrics included commodity

50 textiles, which we define as textiles that are not normally used to provide ballistic protection, and

51 armor textiles. Figures 2 and 3 show images of the fabrics at $10 \times$ and $250 \times$ magnification,

52 respectively.

Army Combat Uniform (ACU) textile is a ripstop woven material constructed from a

54 fiber blend of staple rayon, para-aramid, and nylon fibers. It is similar to the fabric used in the

55 U.S. Army battle dress uniform (BDU). Silk fabric tested in this study was a single jersey knit.

56 Silkworm-derived silk is a considered a continuous filament yarn because the fibers are

57 significantly longer than those typically observed in a natural staple yarn like wool or cotton,

58 although fiber ends are evident within the textile. Light KK and Heavy KK are two staple

59 Kevlar knits used in a variety of consumer goods, with a typical filament length of 20-50 mm

60 (based on manual separation and inspection). The final commodity fabric was single jersey

61 polyester knit. Polyester is representative of typical lightweight, stretchable, synthetic 
62 commercial comfort fabrics. Like silk, polyester is nominally a continuous filament knit,

63 although some fiber ends are apparent when the knit is inspected closely.

64 K706 is a woven ballistic fabric constructed from true continuous filament (no fiber ends

65 are apparent) 600d KM2 Kevlar yarns, and is representative of a torso body armor textile.

Three ballistic felts were also evaluated. Hydro-entangled Dyneema (HED) is an

67 experimental material made from ultra-high molecular weight polyethylene (UHMWPE).

68 ArmorFelt is a commercially produced hybrid felt, composed of both aramid and UHMWPE

69 filaments. TexTech is a commercial textile containing both felted and woven aramid material

70 layers. The material layers are held together with needle punched staple aramid yarns. TexTech

71 fabric is notably heavier than the other materials tested.

\subsubsection{Continuous filament knits}

Table 2 shows properties of the continuous filament knit aramids (CFKA) evaluated.

75 Prototype CFKA was first produced on a lab scale circular knitting machine, the Lawson

76 Hemphill Fiber Analysis Knitter Sampler (FAK-S), using continuous filament 600d KM2 Kevlar

77 yarns. Single-jersey CFKA tubes 7-cm in diameter were fabricated and were cut to create

78 approximately 20-cm-wide strips for ballistic tests. Figure 4 compares the Prototype CFKA and

79 Heavy KK staple knit. The high population of fiber ends is clearly visible in the commodity

80 product, while few fiber ends are evident in the CFKA material.

81 Following proof-of-concept testing, four single jersey, CFKA fabrics were knit at a pilot-

82 scale using a commercial circular knitting machine at the Polartec, LLC production facility in

83 Lawrence, MA. Each sample was knit from one of four potential KM2 yarn deniers: 400d, 500d,

84 600d, and 850d, with all knits having similar numbers of courses and wales per unit length. 
85 Figure 5 shows micrographs of the pilot CFKAs. All fabrics were knit on an $18 \mathrm{cut}, 76.2 \mathrm{~cm}$

86 cylinder knitting machine with 45 input feeds. Machine settings were adjusted to maintain

87 similar course and wale counts between fabrics. Extracted yarn tenacity testing (not shown)

88 indicated that yarn strengths dropped by $10-25 \%$ due to the knitting process. Compared to the

89 prototype CFKA, the pilot CFKA knits have a higher number of courses and wales per unit

90 length.

91

$92 \quad 2.2$ Test methods

$93 \quad 2.2 .1$ Tensile testing

94 Tensile testing is reported for ACU, silk, Heavy KK, K706, ArmorFelt, and Prototype

95 CFKA materials. Rectangular strips $25.4 \mathrm{~cm} \times 7.62 \mathrm{~cm}$ of each fabric were cut from bulk, with

96 the sample edges parallel to the warp and weft directions for the woven materials, and parallel to

97 the courses and wales for the knit materials. Both ends of each strip were folded over $2.54 \mathrm{~cm}$

98 and sewn to increase the thickness of the fabric in the gripping region, thus creating specimens

99 with $15.2 \mathrm{~cm} \times 7.62 \mathrm{~cm}$ rectangular gage areas. To perform the test, fabric specimens were

100 loaded into an MTS Synergie load frame using mechanical screw grips, with the long specimen

101 direction parallel to the load path. A $5 \mathrm{kN}$ load cell was used for the K706, ArmorFelt, and ACU

102 samples, while a $500 \mathrm{~N}$ load cell was used for the silk, Heavy KK, and CFKA materials. Fabrics

103 were pulled at a rate of $16 \mathrm{~mm} / \mathrm{min}$.

104

105

\subsubsection{Ballistic resistance characterization}

106 The projectile used in ballistic tests was a glass sphere with a nominal diameter and

107 weight of $6.0 \mathrm{~mm}$ and $0.28 \mathrm{~g}$ respectively (BB Bastard, Toronto, Canada). This projectile is 
108 used, rather than a more typical steel projectile, to better match the size and mass of a gravel

109 particle that would be launched by a buried explosive. A helium driven, smooth bore gas gun

110 was used to accelerate the projectiles. Two light chronographs made independent measurements

111 of projectile velocity, with the average velocity value reported.

112 Two series of ballistic experiments were performed: the first series compared baseline

113 materials to the prototype CFKA, while the second series evaluated the pilot-scale materials. As

114 will be discussed in more detail below, the differences in test conditions were due to practical

115 concerns (such as limited material availability), but are believed to produce comparable data sets.

116 Due to the low areal densities of the present targets, conventional ballistic test methods (e.g.

117 MIL-STD-662, NIJ Standard 0101.06) intended for evaluation of torso body armor were not 118 appropriate.

119 In the first series each target was subject to nine ballistic impacts. Impact locations were 120 marked according to a predetermined, staggered impact pattern. To simulate realistic backing 121 conditions, targets were wrapped around synthetic gelatin cylinders that measured approximately

$12215.2 \mathrm{~cm}$ in diameter and $30.5 \mathrm{~cm}$ in height. The gelatin is based on a physically associated

123 polymer mixed with a low volatility non-aqueous solvent, formulated to satisfy the calibration

124 standards for $20 \%$ ordnance gelatin $[15,16]$. Target dimensions were approximately $46.5 \mathrm{~cm} \times$

$12530.5 \mathrm{~cm}$. Velcro strips were sewn to the target edges to secure it around the gelatin cylinder, 126 with the targets pre-tensioned slightly to eliminate any slack and ensure a close fit to the gel 127 backing. Shot velocities for each target were selected to achieve a mixture of penetrating and 128 non-penetrating responses. $V_{50}$ limits were calculated using maximum likelihood estimation to 129 fit the data with a cumulative distribution function for a normal distribution. 
131 modifications. The number of shots per tests was increased to 15 and synthetic gelatin was

132 replaced with natural $20 \%$ ordnance gelatin, wrapped with a single layer of commercial $12.5-\mu \mathrm{m}$

133 cling wrap polyethylene film to prevent moisture intrusion into the targets. Additionally, targets

134 were affixed to the cylinder using nylon straps. Finally shot speed selection followed the method 135 prescribed by a modified Langlie technique [17].

136 The differences in test conditions for the two ballistic test series (shots per target,

137 synthetic versus natural gelatin, target mounting) are relatively minor. To ensure that the two 138 test series produce comparable data, experiments on five silk, ACU, Light KK, and Heavy KK 139 targets were performed as part of both the first test series and second test series. The $V_{50}$ values 140 were found to differ between test series, on average, by 3\%. Therefore, all results from both test 141 series can be reasonably compared as a single data set.

142 A baseline $V_{50}$ for the ballistic gelatin, without a fabric target, was measured by defining 143 a "penetration" as an impact in which the projectile remained embedded in the cylinder. This 144 gelatin $V_{50}$ was found to be $130 \mathrm{~m} / \mathrm{s}$ for the synthetic gelatin cylinder (first test series), and 107 $145 \mathrm{~m} / \mathrm{s}$ for the natural gelatin cylinder wrapped with cling wrap (second test series). For simplicity, 146 we use the average value, $119 \mathrm{~m} / \mathrm{s}$, as a representative gel penetration velocity for benchmarking 147 target performance.

\section{$149 \quad$ 2.2.3 Quasistatic puncture}

150 Quasistatic puncture tests were conducted on ACU, Heavy KK, K706, ArmorFelt, 400d 151 SJ, and 850d SJ samples. Samples were tested in a reverse puncture configuration so that the 152 projectile position remained fixed relative to ground, simplifying imaging by providing a 
153 common frame of reference for both the projectile and the video camera (Figure 6). A glass

154 sphere was epoxied to the end of a steel rod and threaded into a fixed load cell. Fabric coupons

155 were clamped into a square fixture with inner aperture of $10.2-\mathrm{cm} \times 10.2-\mathrm{cm}$ that was

156 subsequently mounted on the crosshead using C-clamps. As the crosshead moved downward at

$15730 \mathrm{~mm} / \mathrm{min}$, the fabric was slowly stretched over the projectile until punctured.

158 With the aid of a high speed camera it was possible to record images of the puncture

159 event. A Photron Fastcam SAS RV camera was used to take pictures at 100,000 fps with a

$1601 / 517000 \mathrm{~s}$ shutter speed. The recording timeframe consisted of $70 \%$ pre-trigger to ensure the

161 event was captured. The load cell output was recorded on a Tektronix DPO71245C oscilloscope.

162 When the load suddenly dropped due to puncture, the oscilloscope output a $2.5 \mathrm{~V}$ pulse to the

163 Photron camera initiating its trigger. The sample was illuminated using two Dedocool $250 \mathrm{~W}$

164 lamps each powered with a CoolT3 power supply.

165

166 3. Results

$167 \quad 3.1$ Tensile testing

168 Figure 7 a shows the raw load versus displacement data from tensile testing. The load

169 data is presented on a log axis to capture all sample behaviors, from the very high loads ( > 1000

$170 \mathrm{~N})$ generated by the K706 samples to the very low loads (1-10 N) produced by the CFKA

171 material. The K706 and ACU samples show loads to failure, while for other samples loading

172 was stopped prior to failure. It is evident from the data that the K706, ArmorFelt, and ACU

173 textiles are considerably more resistant to tensile elongation compared to the knitted materials.

174 Figure $7 \mathrm{~b}$ presents the tensile data as specific stress versus true strain, where specific

175 stress is calculated by normalizing the fabric load by the product of initial sample width and areal 
176 density, and true strain is $\ln \left(L / L_{o}\right)$ where $L_{o}$ is the initial sample length and $L$ is the elongated

177 sample length. Also shown inset in the figure is a tabulation of the specific linear modulus of

178 each sample, calculated over the strain range of 1-3\%. The modulus data shows that the K706

179 textile is approximately $10^{3}-10^{4} \times$ stiffer in-plane compared to the knits, the ACU fabric is

180 approximately $10-100 \times$ stiffer than the knits, and the ArmorFelt is roughly $10 \times$ stiffer than the

$181 \quad$ CFKA and silk knits.

182

\subsection{Ballistic characterization}

184 The $V_{50}$ performance of all targets is presented in Table 3. Figure 8 shows the results

185 from baseline materials and prototype CFKA, with dashed lines to provide guides for

186 interpolating the overall performance of different material classes. Also shown in the figure is

187 the nominal $V_{50}$ value for the ballistic gel alone. Micrographs of failure zones are presented in

188 Figure 9. Images are of the lowest velocity, penetrating impact.

Commodity fabrics provided the lowest perforation resistance on a per weight basis, and

190 all commodity fabrics collapsed onto a single performance curve. The results indicate that staple

191 aramid offers no ballistic advantage over comfort fabrics such as silk and polyester. Based on

192 these results, the ballistic perforation resistance of these materials correlates most directly to the

193 areal density of the targets, and does not appear to be strongly influenced by details of fabric

194 construction or filament mechanical properties. Woven K706 provided significantly better

195 perforation resistance than the commodity materials, as would be expected since this textile has

196 been engineered for ballistic protection. The failure region for K706 shows evidence of

197 windowing (in-plane yarn spreading and separation) and filament failure. 
Dwivdei et. al, "Low Velocity Ballistic Behavior... Knit Aramid"

The CFKA prototype better perforation resistance than the commodity materials, but not 212 textile.

as well as woven $\mathrm{K} 706$. At $270 \mathrm{~m} / \mathrm{s}$ the prototype CFKA $V_{50}$ is approximately $40 \%$ greater than that of commodity targets and only $7 \%$ below K706. CFKA and Light KK targets are both single jersey knits with similar areal densities. The sizable difference in performance between the two materials suggests that staple yarns degrade ballistic performance, and significantly better knit ballistic performance can be achieved by using continuous filament yarn. CFKA failure shows a distinct, local yarn failure with closely grouped fiber ends, unlike the commodity fabrics which tend to show a less distinct failure location.

Of the baseline materials, felts demonstrated the highest mass normalized $V_{50}$ values. HED and ArmorFelt perform similarly over the range of areal densities tested here. Felting did not appear to enhance the ballistic properties of the TexTech fabric. Its $V_{50}$ was $414 \mathrm{~m} / \mathrm{s}$ at 844 gsm which is approximately the performance that would be expected of K706 at that areal density. Due to the inherent entangled nature of felts it is difficult to identify if perforation is due to fiber failure or simply fiber untangling and separation of pre-existing fiber ends for this

The performance of the four pilot CFKA fabrics is presented in Figure 10. Data from the commodity knits and the CFKA prototype from the first test series are also included in the figure for comparison. There is a positive correlation between yarn denier and $V_{50}$. The Pilot $400 \mathrm{~d}$ and Pilot 500d samples performed approximately the same as commodity knits. However, the Pilot 600d and Pilot 850d fabrics have appreciably better ballistic behavior. It is noteworthy that the pilot CFKAs underperformed relative to the prototype CFKA, which may be due to the differences in knit geometry or yarn damage induced by the different knitting machinery. 
Dwivdei et. al, "Low Velocity Ballistic Behavior... Knit Aramid" 238 forces on the CFKA membrane at failure.

\subsection{Quasistatic puncture} peak load point.

Figure 11 shows load versus displacement for the quasistatic puncture experiments, and Table 4 shows the peak puncture load values, energy to failure, and load and energy values normalized by the textile areal density. It is evident that the commodity materials (ACU, Heavy KK, and Polyester) show the lowest puncture values while the K706, ArmorFelt, 400d SJ and 850d SJ samples show significantly higher puncture loads. All samples failed catastrophically and suddenly, with the exception of the ArmorFelt sample which showed a long and gradual load reduction during failure. The polyester undergoes significantly higher displacement to failure compared to the other materials. Figure 12 shows images of three of the samples near their failure point. The K706 sample shows much less deformation compared to the polyester and ArmorFelt samples, with the ArmorFelt showing prevalent fiber sliding and unwinding after the

Figure 13 shows high speed images for three of the knit specimens: Heavy KK, 400d SJ, and $850 \mathrm{~d}$ SJ. The images indicate that for both the staple knit and CFKA the puncture process begins after a single yarn loop breaks. Following loop failure the hole expands and stretches over the projectile causing a combination of filament failure and windowing. It appears that the hole grows more quickly in the CFKAs, compared to the staple knit, likely due to the higher

\section{Discussion}

The ballistic test results show that all commodity textile data collapses onto a single $V_{50}$

242 versus areal density performance curve. The uniformly low ballistic behavior of these materials

243 is most likely driven by their low effective yarn strengths. The silk and polyester knits are 
Dwivdei et. al, "Low Velocity Ballistic Behavior... Knit Aramid"

244 continuous filament, but are inherently low strength fibers (the strength of Kevlar filaments, for 245 example, are likely to be roughly 10× higher than silk [18]). The ACU, Light KK, and Heavy

246 KK may be composed of higher strength filaments (nylon and Kevlar), but as staple materials

247 their yarn strength will be driven by filament interactions (twist and friction) rather than merely

248 the ideal filament strength $[19,20]$.

249 Comparing the staple aramid knits (Light KK and Heavy KK) versus the high denier

250 (600d and 850d) CFKA knits, it is evident from both quasistatic puncture and ballistic data that

251 continuous aramid fibers lead to better performance compared to entangled, short aramid fibers.

252 The fact that yarn tenacity decreased somewhat after knitting suggests that, if details of the

253 knitting process could be addressed to minimize yarn strength reductions, then knit ballistic

254 resistance could increase further. Yarn tenacity could also explain why the prototype CFKA

255 material slightly outperformed the pilot-scale CFKA, since the prototype loom operated at a

256 slower speed and may have been more gentle in handling the yarns. The lower number of wales

257 and courses per unit length for the prototype CFKA could also contribute to the difference in

258 performance, although systematic experimentation would be required to validate this trend.

259 For the pilot materials, the knits composed of heavier denier yarns (600d and 850d)

260 provided higher ballistic resistance than the knits composed of lower denier yarns (400d and

261 500d). In fact, the low denier pilot CFKA knits did not show a measureable increase in ballistic

262 performance relative to the staple knits. This contrast between high and low denier knits can be

263 explained by considering the failure images during quasistatic puncture of various knits in Fig.

26411 , which shows that the failure of a single yarn triggers an unraveling of the knit structure that

265 enables puncture. A single knit layer composed of heavy yarns will provide high resistance, as

266 high loads are necessary to fail a single, high denier yarn. A multi-layer knit target composed of 
Dwivdei et. al, "Low Velocity Ballistic Behavior... Knit Aramid"

267 finer yarns can provide equivalent resistance only if the membrane loads are being shared evenly

268 between the layers and amongst the yarns. During realistic ballistic loading, variations in layer

269 tension, orientation, boundary conditions, etc. are likely to lead to non-uniformities in yarn

270 loading. If these non-uniformities lead to failure of any single yarn within the multi-layer

271 assembly, a cascading series of failures and unraveling will occur to catastrophically fail the

272 entire target assembly. Therefore knits can be considered "weakest link" architectures in which

273 their ultimate performance is driven by the weakest material element in the assembly, so that a

274 single-layer knit composed of heavy yarns is likely to perform better than a weight-matched

275 target of multiple layers of a lower areal density knit composed of finer yarns. A caveat to this

276 hypothesis is that the data does not show a continuous increase in per-mass ballistic performance

277 with increasing yarn denier, i.e. there appears to be a significant difference in performance for

278 600d versus 500d pilot knits, but little difference in behavior between 600d and 850d pilot knits.

279 A more systematic study is required to separate the specific roles of yarn denier, architecture,

280 and knitting process history on ballistic perforation. For example, in the present pilot knits, the

281 course and wale spacing remains relatively constant for all yarn deniers; perhaps a more

282 systematic trend in perforation resistance would be observed if the course and wale sizes

283 increased proportionally with yarn denier.

284 Comparing the CFKA and woven K706 textile, both the puncture data and ballistic data

285 show that the woven architecture provides superior perforation resistance. This trend is most

286 likely due to the fact that the woven architecture can survive multiple yarn failures before

287 experiencing catastrophic failure, while the knits are likely to unravel after a single yarn failure.

288 A more subtle trend is apparent by noting that the difference in performance between K706 and

289 CFKA increases with areal density. This trend indicates that knits may perform more 
290 comparably to wovens at low areal densities and velocities, while losing efficiency as velocity 291 and energy increase. This behavior is consistent with prior work [12-13], and can be explained

292 by considering the low in-plane elastic modulus, and therefore stress wave propagation speed,

293 for knits compared to wovens (Fig. 7). As impact velocity increases, the knit transmits loads

294 over a more limited lateral distance compared to wovens, resulting in less material volume

295 available for energy absorption and a lower per-mass ballistic performance. These results

296 suggest that conventional knits, as studied in this manuscript, are best suited for low-velocity

297 ballistic events and low-density armors.

298 Interestingly, the felts provided the best overall ballistic efficiency. Prior comparisons of

299 felts and wovens by Liable and Henry [21, 22] showed that nylon felts provided significantly

300 better ballistic efficiency at velocities up to $400 \mathrm{~m} / \mathrm{s}$, but suggested that wovens become more

301 efficient at higher velocities. They attributed this behavior to the fact that, at low velocities, the

302 felts undergo significantly more deformation than the wovens and therefore can absorb energy

303 over longer time periods. In contrast, at high velocities, the very low in-plane and transverse

304 wave speeds of the felts compared to wovens localized the failure and limited the volume of

305 material participating in the ballistic interaction. These rate-dependent mechanisms are

306 analogous to those observed in the comparative behavior of knits and wovens.

307 Some additional insight can be gained by plotting the ballistic data versus the quasistatic

308 puncture data. We define a "specific ballistic energy" $\bar{U}$ (units of J/gsm) as

309

$$
\bar{U}=\frac{m_{p}\left(V_{50}^{2}-V_{50, \mathrm{gel}}^{2}\right)}{2 \rho_{A}}
$$


Dwivdei et. al, "Low Velocity Ballistic Behavior... Knit Aramid"

312 where $V_{50}$ and $V_{50 \text {, gel }}$ are the $V_{50}$ values of the target and the gel block alone (using the average

313 value measured for the natural and synthetic gelatin cylinders), respectively, $m_{p}$ is the projectile

314 mass, and $\rho_{A}$ is the areal density of the target. The specific ballistic energy represents a mass-

315 normalized ballistic energy absorption capability of the target. Values are tabulated in Table 4,

316 using the lowest areal density ballistic data available, for materials that were also evaluated for

317 quasistatic puncture resistance. Also tabulated is the puncture energy to failure, normalized by

318 the areal density of the puncture samples.

319 Figure 14 plots specific ballistic energy versus specific puncture energy. Generally, 320 increasing puncture energy correlates with increasing ballistic energy. For the ArmorFelt and

321 knitted materials (Polyester, Pilot 400d, and Pilot 850d) the puncture energies are roughly 2-3×

322 higher than the ballistic energies. These high puncture energies for these materials are due to

323 their high deformations to failure under quasistatic conditions; under ballistic conditions, loading

324 and failure will be more localized and its mechanical efficiency will be reduced.

325 Figure 14 also shows that while Pilot 850d and Pilot 400d CFKA show comparable

326 specific puncture energies, the Pilot 850d provides significantly higher ballistic efficiency. This

327 result supports our earlier "weakest link" hypothesis. Since the quasistatic experiments were

328 performed on single layer materials, layer-to-layer load sharing is not a concern and the

329 normalized puncture energies are comparable between the $850 \mathrm{~d}$ and $400 \mathrm{~d}$ materials. At higher

330 speeds and comparing a multi-layer material 400d target to a single-layer $850 \mathrm{~d}$ target, the lower

331 relative performance of the 400d target suggests inefficient load-sharing between the plies and

332 possibly between yarns. Additional testing, supported by numerical simulations [23], should

333 provide further insight into these considerations. 
Finally, returning to the tensile testing data (Fig. 7), the elastic modulus trends quantify

335 what is immediately apparent when manually handling the various textiles: the knits are easy to

336 stretch, while the woven fabrics are essentially un-stretchable along their principal yarn

337 directions. The felts provide some extensibility, but after small strains this extension is mostly

338 irreversible. For this reason, modern compression garments and athletic wear, including athletic

339 shoes, are composed of knitted textiles. Similarly, to meet emerging needs for close-fitting

340 ballistic undergarments and extremity protection, only knits are universally suitable, while

341 wovens, felts, and other non-stretchable materials would only be practical as patches in garment

342 areas that are subject to low stretch. Of the knits evaluated in this study, the CFKA materials

343 provide the best combination of high stretchability and good ballistic efficiency.

\section{5. Conclusions}

This study provides the first systematic evaluation of the ballistic barrier properties of

347 knits composed of high performance, continuous filament yarns. The results show that the

348 continuous filament knitted aramids provide a unique combination of stretchability and mass-

349 efficient perforation resistance relative to commodity materials, woven ballistic textiles, and

350 ballistic felts. The data also indicates that barriers composed of fewer, heavier knit layers should

351 provide performance superior to equal mass barriers composed of a higher number of lighter knit 352 layers.

At present, only continuous knit aramids have been evaluated. Knits composed of other

354 high performance continuous filament materials such as UHWMPE should also provide good

355 ballistic performance. Similarly, the present study only considered one knit style, single jersey.

356 The diverse range of additional knit styles available suggest that further optimization of 
357 performance is possible, perhaps to include the creation of a set of materials with tradeoffs in

358 stretch versus ballistic performance. Finally, finite element models of ballistic impact into

359 knitted materials are under development to provide predictive design capabilities for future

360 knitted ballistic materials.

\section{Acknowledgements}

The authors gratefully acknowledge Dr. James Singletary of DuPont and Moshe Rock of Polartec LLC for the pilot-scale CFKA knitted materials; Jeff Perry of NSRDEC for assistance with Prototype CFKA knitting; Wai Chin or ARL for assistance with tensile testing; Dr. Randy Mrozek and Dr. Joe Lenhart of ARL for the synthetic gelatin material; and Rob Kinsler of ARL for assistance in fabrication of natural gelatin cylinders. This research was supported in part by an appointment to the Postgraduate Research Participation Program at the U.S. Army Research Laboratory administered by the Oak Ridge Institute for Science and Education through an interagency agreement between the U.S. Department of Energy and USARL.

\section{References}

1. B. A. Cheeseman and T. A. Bogetti. "Ballistic impact into fabric and compliant composite laminates." Comp. Structures. v61 p161-173. 2003.

2. N. V. David, X.-L. Gao, and J. Q. Zheng. "Ballistic resistant body armor: Contemporary and prospective materials and related protection mechanisms." Appl. Mech. Rev. v62 n5 p050802-1 - 050802-20. 2009.

3. Z. Dong, J. M. Manimala, and C. T. Sun. "Mechanical behavior of silica nanoparticleimpregnated Kevlar fabrics." J. Mechanics Materials Structures. v5 n4 p529-548. 2010.

4. Image generated by P. Justin McKee, U.S. Army Research Laboratory. Personal communication. 2015. 
Dwivdei et. al, "Low Velocity Ballistic Behavior... Knit Aramid"

5. R. Postle. "Structural mechanics of knitted fabrics for apparel and composite materials." J. Textile Institute. v92 n3 p80-90. 2001.

6. B. M. MacRory and A. B. McNamara. "Knitted fabrics subjet to biaxial stress - an experimental study." Textile Research Journal. v37 n10 p908-911. 1967.

7. B. M. MacRory, J. R. McCraith, and A. B. McNamara. "Experimental investigation of the biaxial load-extension properties of plain, weft-knitted fabrics." Textile Research Journal. v47 n4 p233-239. 1977.

8. R. Postle and D. L. Munden. "Analysis of the dry-relaxed knitted-loop configuration. Part I: Two-dimensional analysis." J. Textile Institute. v58 n8 p329-351. 1967.

9. W. J. Shanahan and R. Postle. "A theoretical analysis of the plain-knitted structure." Textile Research Journal. v40 n7 p656-665. 1970.

10. A. U. Loginov, S. A. Grishanov, and R. J. Harwood. "Modelling the load-extension behavior of plain-knitted fabric: Part III: Model implementation and experimental verification." J. Textile Institute. v93 n3 p251-275. 2002.

11. J. Kaldor, D. James, and S. Marschner. "Simulating knitted cloth at the yarn level." ACM Trans. Graph. v27 n3 p61-1 - 65-2. 2008.

12. J.W.S. Hearle, and M. A. I. Sultan. "Research on a basic study of the high-speed penetration dynamics of textile materials." Manchester (UK): University of Manchester Institute of Science and Technology. Available from DTIC, Fort Belvoir, VA: ADA003504. May 1974.

13. C. R. Cork and P. W. Foster. "The ballistic performance of narrow fabrics." Int. J. Impact Eng. v34 p495-508. 2007.

14. K.W. Lau and T. Dias. "Knittability of high-modulus yarns." J. Textile Institute. v84 n2 p173-190. 1994.

15. D. T. Casem, A. J. Dwivedi, R. A. Mrozek, and J. L. Lenhart. "Compression response of a thermoplastic elastomer gel tissue surrogate over a range of strain-rates." Int. J. Solids Structures. v51 n11-12 p2037-2046. 2014.

16. Z. I. Kalcioglu, R. Mrozek, R. Mahmoodian, M. R. VanLandingham, J. L. Lenhart, and K. J. Van Vliet. "Tunable mechanical behavior of synthetic organogels as biofidelic tissue simulants." J. Biomechanics. v46 n9 p1583-1591. 2013.

17. T. H. Johnson, L. Freeman, J. Hester, and J. L. Bell. "A comparison of ballistic resistance testing techniques in the Dept. of Defense." IEEE Access. v2 p1442-1455. 2014. 
18. I. Krasnov, I. Diddens, N. Hauptmann, G. Helms, M. Ogurreck. T. Seydel, S. S. Funari, and M. Muller. "Mechanical properties of silk: interplay of deformation on macroscopic an molecular length scales." Phys. Rev. Lett. v100 n048104 p1-4. 2008.

19. N. Pan. "Prediction of statistical strengths of twisted fibre structures." J. Mat. Sci. v28 n22 p6107-6114. 1993.

20. S. L. Phoenix. "Statistical theory for the strength of twisted fiber bundles with applications to yarns and cables." Textile Research Journal. v49 p407-423. 1979.

21. R. C. Laible and M. C. Henry. "A review of the development of ballistic needle-punched felts." U.S. Army Natick Laboratories. Report No. TS-167 70-32-CE. Available from DTIC, Fort Belvoir, VA: AD0707918. Oct. 1969.

22. R. C. Laible and M. C. Henry. "Development of needle-punched felts." American Dyestuff Reporter. v60 n4 p36-41. 1971.

23. P. Justin McKee, A. C. Sokolow, A. K. Dwivedi, and E. D. Wetzel. "Finite element simulation of ballistic impact on single jersey knit fabric." Proc. of Fiber Society 2014 Fall Meeting and Technical Conference, Fibers for the Future. Philadelphia, PA. October 22-24, 2014. 


\section{Tables}

Table 1: Baseline extremity protection materials. Materials above the dashed line are considered "commodity" textiles, while those below the dashed line are considered ballistic textiles. Areal density units of "gsm" are $\mathrm{g} / \mathrm{m}^{2}$.

\begin{tabular}{ccccc}
\hline $\begin{array}{c}\text { Sample } \\
\text { name }\end{array}$ & Description & $\begin{array}{c}\text { Part } \\
\text { number }\end{array}$ & Source & $\begin{array}{c}\text { Areal } \\
\text { density } \\
(\mathrm{gsm})\end{array}$ \\
\hline ACU & "Improved Defender M" Fire Resistant ACU fabric & - & Tencate (Almelo, Netherlands) & 220 \\
Silk & knitted Jersey silk & - & NY Fashion Center (New York City, NY) & 165 \\
Light KK & "light" knitted staple Kevlar & 145KV30 & Green Mountain Knitting (Milton, VT) & 225 \\
Heavy KK & "heavy" knitted staple Kevlar & 437 KV17 & Green Mountain Knitting (Milton, VT) & 328 \\
Polyester & knitted polyester & - & Jo-Ann Fabrics (Bel Air, MD) & 96 \\
\hline K706 & woven 600d KM2 Kevlar & Style 706 & JPS Composites (Anderson, SC) & 180 \\
HED & hydroentangled Dyneema felt & - & UK Ministry of Defense & 200 \\
ArmorFelt & Armorfelt, hybrid aramid/PE felt & - & Kennon Covers Inc. (Sheridan, WY) & 250 \\
TexTech & hybrid felt / woven fabric & 9010 & TexTech Industries (Portland, ME) & 844 \\
\hline \hline
\end{tabular}

Table 2: CFKAs evaluated. The prototype CFKA was produced on a lab-scale circular knitting machine, while the knits below the dashed line were produced using a production circular knit machine.

\begin{tabular}{cccccc}
\hline \hline $\begin{array}{c}\text { Sample name } \\
-\end{array}$ & $\begin{array}{c}\text { Yarn size } \\
\text { (den) }\end{array}$ & $\begin{array}{c}\text { Stitch meter } \\
\text { (in/rev) }\end{array}$ & $\begin{array}{c}\text { Wales } \\
\text { per cm }\end{array}$ & $\begin{array}{c}\text { Courses } \\
\text { per cm }\end{array}$ & $\begin{array}{c}\text { Areal density } \\
\text { (gs m) }\end{array}$ \\
\hline Prototype CFKA & 600 & - & 5.0 & 9.8 & 200 \\
\hline Pilot 400d & 400 & 270 & 8.7 & 13 & 219 \\
Pilot 500d & 500 & 275 & 8.4 & 12 & 288 \\
Pilot 600d & 600 & 275 & 8.9 & 10 & 338 \\
Pilot 850d & 850 & 325 & 8.8 & 12 & 433 \\
\hline \hline
\end{tabular}


Table 3: Ballistic performance $\left(V_{50}\right.$ in $\mathrm{m} / \mathrm{s}$ ) for all fabrics. Materials above the first dashed line are commodity textiles, while materials between the two dashed lines are ballistic textiles. All materials above the solid line were evaluated according to the first, 9 -shot test protocol, while materials below the solid line were evaluated according to the second, 15 -shot test protocol.

\begin{tabular}{ccccccc}
\hline \hline Material & \multicolumn{7}{c}{ Number of plies } \\
& 1 & 2 & 3 & 4 & 6 & 8 \\
\hline ACU & - & 205 & - & - & - & - \\
Silk & - & 190 & - & 233 & - & - \\
Light KK & - & 213 & - & - & - & - \\
Heavy KK & 192 & 240 & - & - & - & - \\
Polyester & - & - & - & 198 & - & 230 \\
\hline K706 & - & 291 & - & - & 460 & - \\
HED & 298 & 367 & 403 & - & - & - \\
ArmorFelt & 327 & 410 & - & - & - & - \\
TexTech & 414 & - & - & - & - & - \\
\hline Prototype CFKA & - & 270 & - & - & - & - \\
\hline Pilot 400d & - & 205 & 233 & - & - & - \\
Pilot 500d & 201 & 228 & - & - & - & - \\
Pilot 600d & 231 & 266 & - & - & - & - \\
Pilot 850d & 245 & 274 & - & - & - & - \\
\hline \hline
\end{tabular}

Table 4: Peak force, energy to failure, and areal-density-normalized values from puncture testing. Also tabulated, for comparison, is ballistic energy at $V_{50}$ normalized by the target areal density, based on the lowest areal density ballistic experiments for each sample.

\begin{tabular}{cccccc}
\hline \hline Material & $\begin{array}{c}\text { Puncture } \\
\text { force } \\
(\mathrm{N})\end{array}$ & $\begin{array}{c}\text { Specific } \\
\text { puncture force } \\
(\mathrm{N} / \mathrm{gsm})\end{array}$ & $\begin{array}{c}\text { Puncture } \\
\text { energy } \\
(\mathrm{J})\end{array}$ & $\begin{array}{c}\text { Specific } \\
\text { puncture energy } \\
(\mathrm{mJ} / \mathrm{gsm})\end{array}$ & $\begin{array}{c}\text { Specific } \\
\text { ballistic energy } \\
(\mathrm{mJ} / \mathrm{gsm})\end{array}$ \\
\hline ACU & 206 & 0.94 & 1.2 & 5.4 & 8.9 \\
Heavy KK & 236 & 0.72 & 1.4 & 4.1 & 9.7 \\
Polyester & 122 & 1.27 & 2.4 & 24.5 & 9.2 \\
K706 & 897 & 4.98 & 5.9 & 32.8 & 27.4 \\
ArmorFelt & 1092 & 4.37 & 23.1 & 92.3 & 52.0 \\
Pilot 400d & 867 & 3.96 & 4.9 & 22.5 & 8.9 \\
Pilot 850d & 1357 & 3.13 & 9.7 & 22.4 & 14.8 \\
\hline \hline
\end{tabular}


Dwivdei et. al, "Low Velocity Ballistic Behavior... Knit Aramid"

\section{Figures}

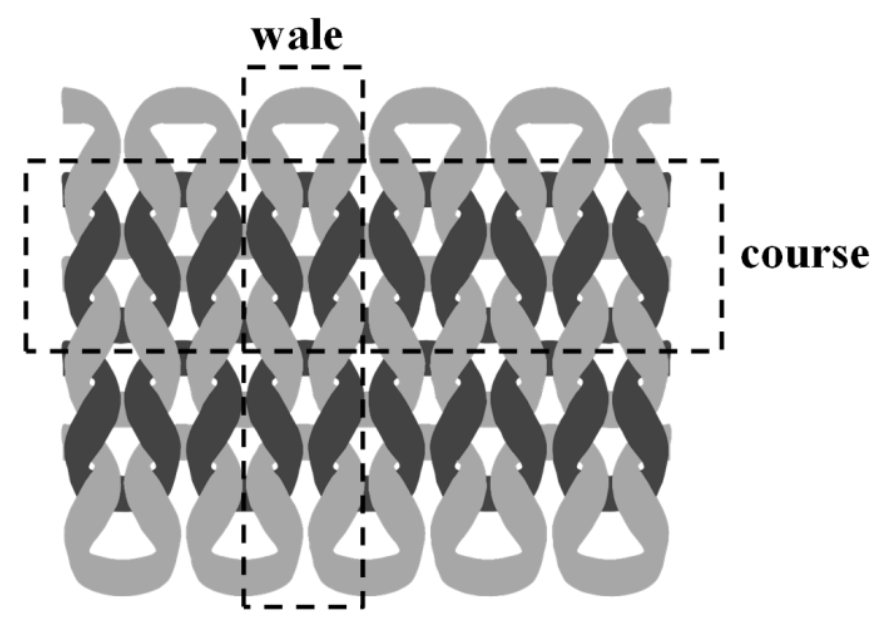

Figure 1: Single jersey knit structure [4]. 
Dwivdei et. al, "Low Velocity Ballistic Behavior... Knit Aramid"
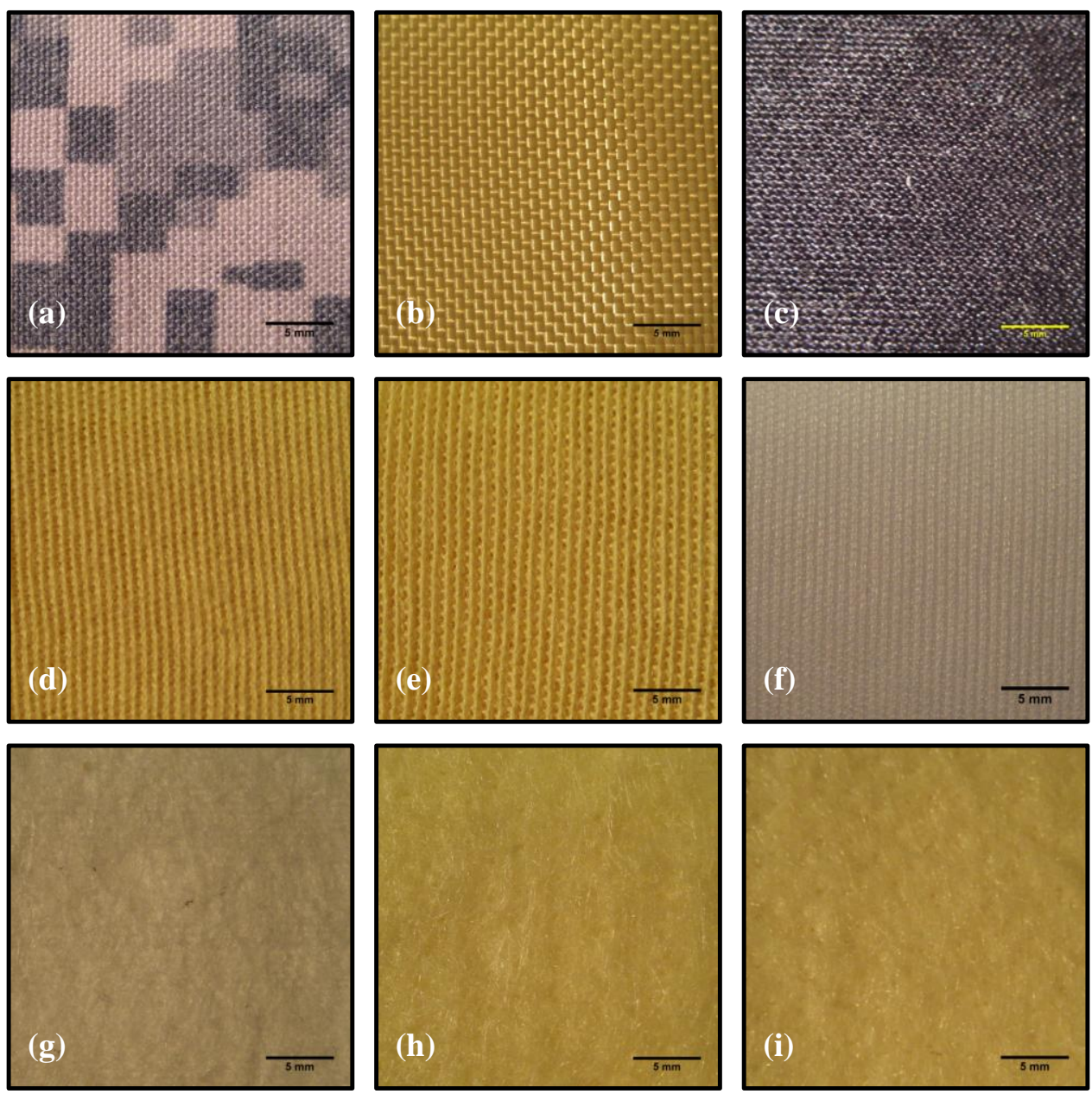

Figure 2: Micrographs of evaluated fabrics at 10× magnification. Scale bars at $5 \mathrm{~mm}$. (a) ACU, (b) K706, (c) Silk. (d) Light KK, (e) Heavy KK, (f) Polyester, (g) HED, (h) ArmorFelt, and (i) TexTech. 
Dwivdei et. al, "Low Velocity Ballistic Behavior... Knit Aramid"
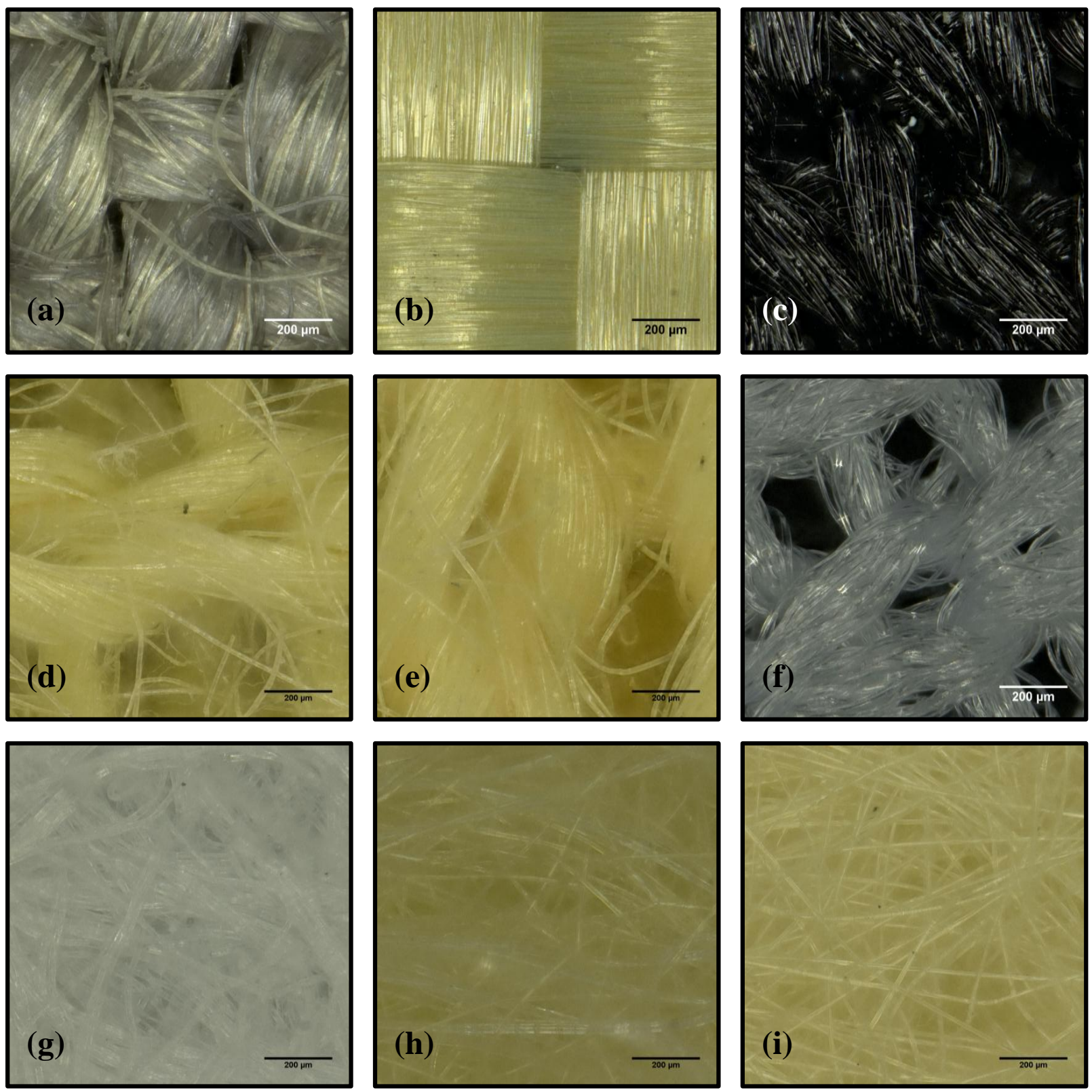

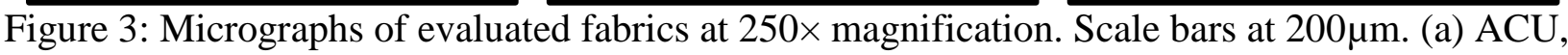
(b) K706, (c) Silk. (d) Light KK, (e) Heavy KK, (f) Polyester, (g) HED, (h) ArmorFelt, and (i) TexTech. 
Dwivdei et. al, "Low Velocity Ballistic Behavior... Knit Aramid"

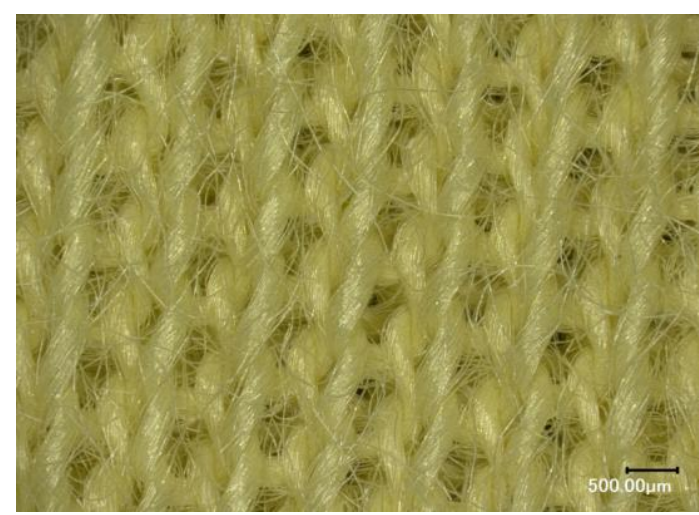

(a)

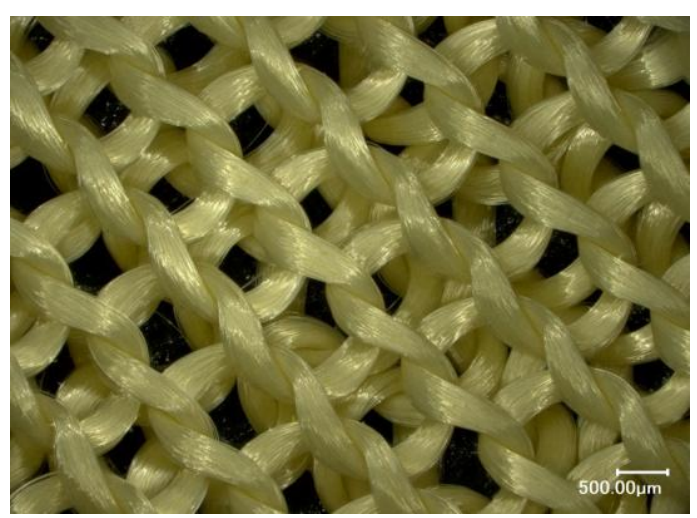

(b)



(c)

Figure 4: Comparison of (a) Heavy KK staple knit and (b) CFKA prototype. (c) Micrograph of Prototype CFKA at $250 \times$ magnification. 
Dwivdei et. al, "Low Velocity Ballistic Behavior... Knit Aramid"

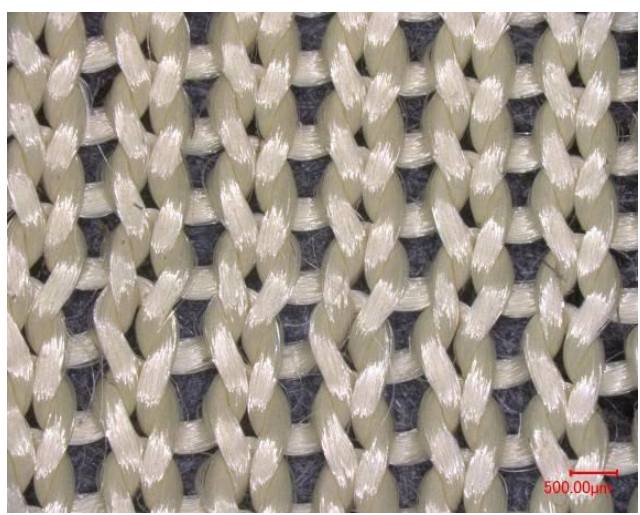

(a)

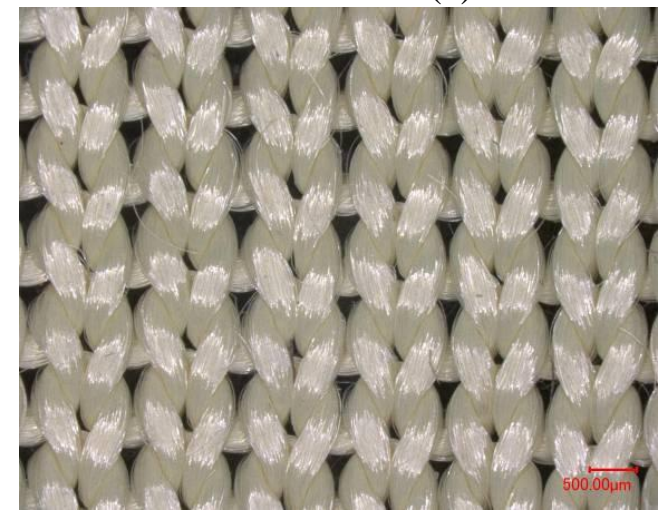

(c)

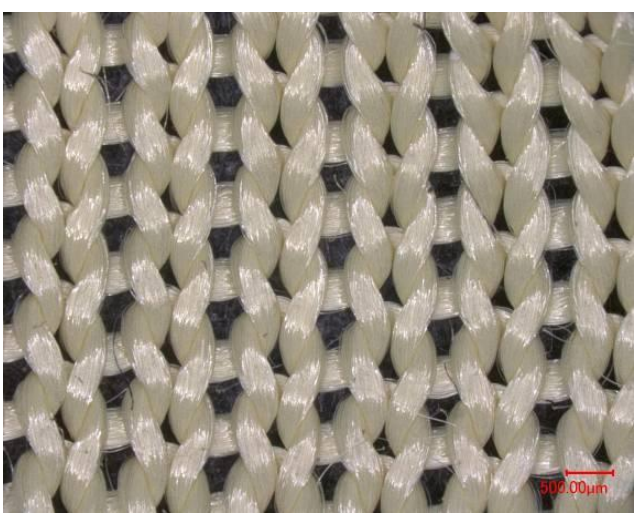

(b)

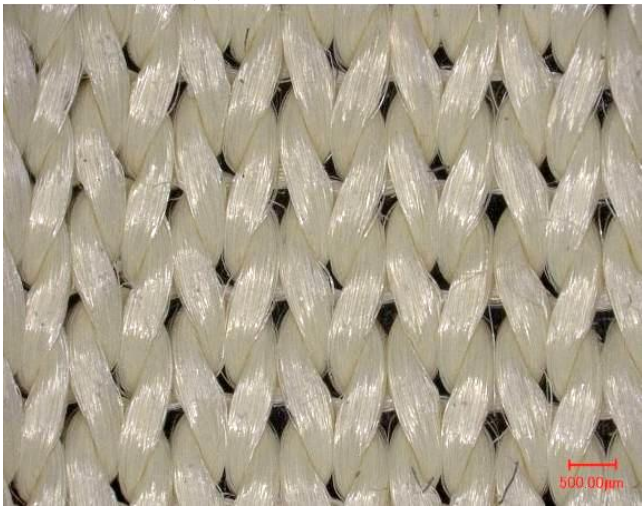

(d)

Figure 5: Pilot knits with varying yarn linear densities of (a) 400d, (b) 500d, (c) 600d, and (d) $850 \mathrm{~d}$. 
Dwivdei et. al, "Low Velocity Ballistic Behavior... Knit Aramid"
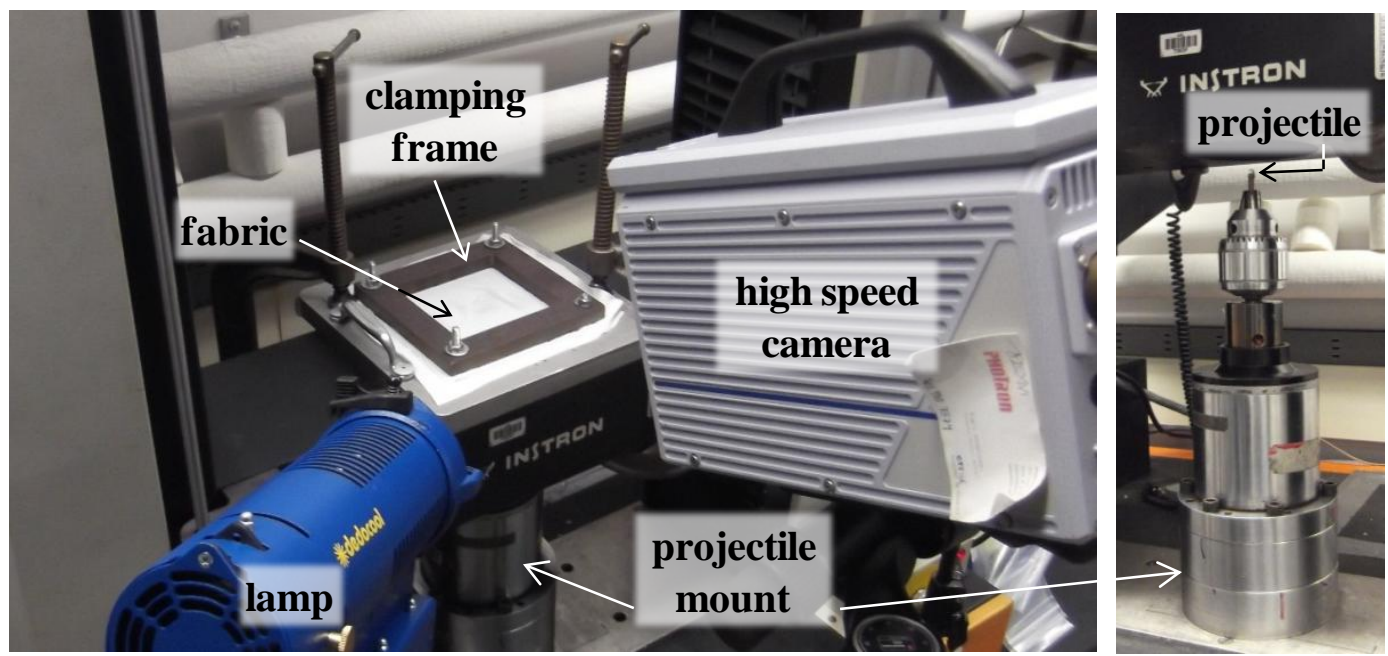

(a)

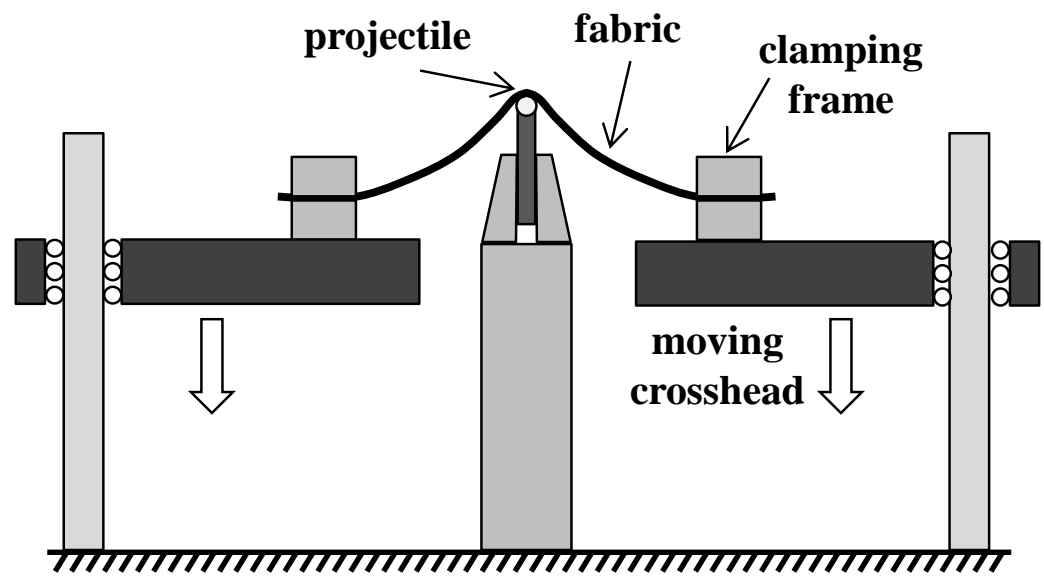

(b)

Figure 6: Quasistatic puncture apparatus (a) photograph and (b) schematic. 
Dwivdei et. al, "Low Velocity Ballistic Behavior... Knit Aramid"

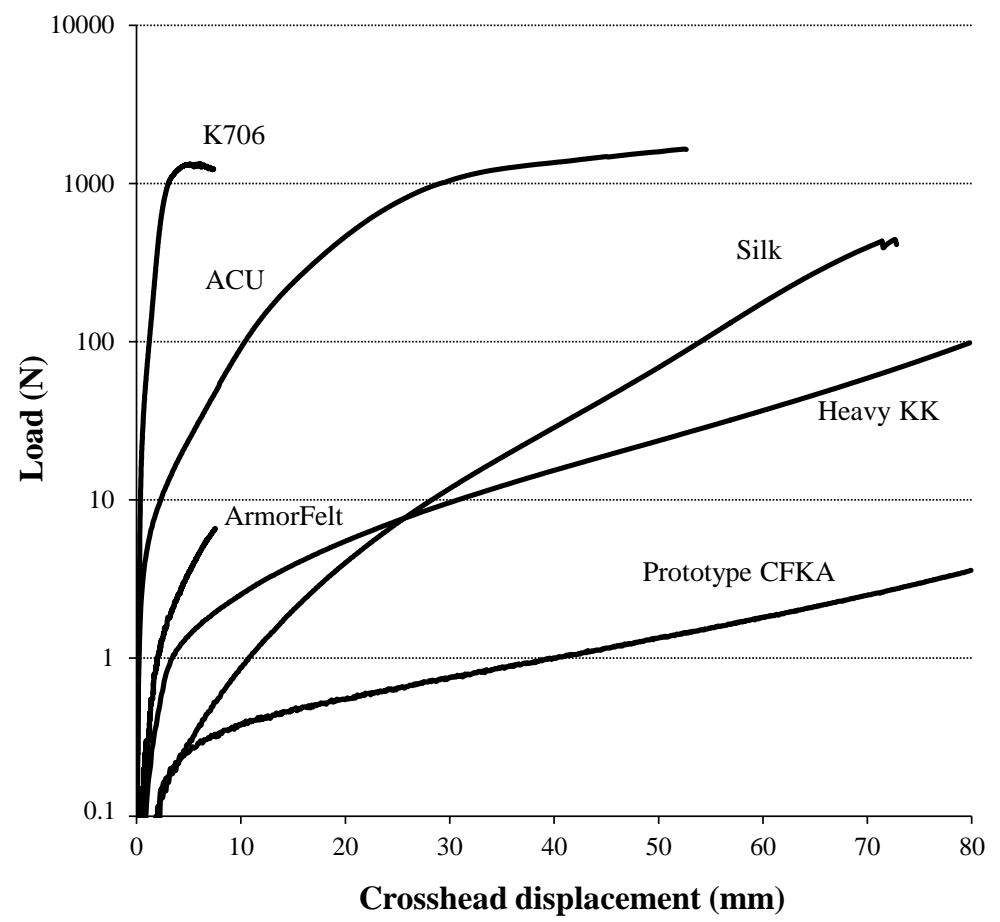

(a)

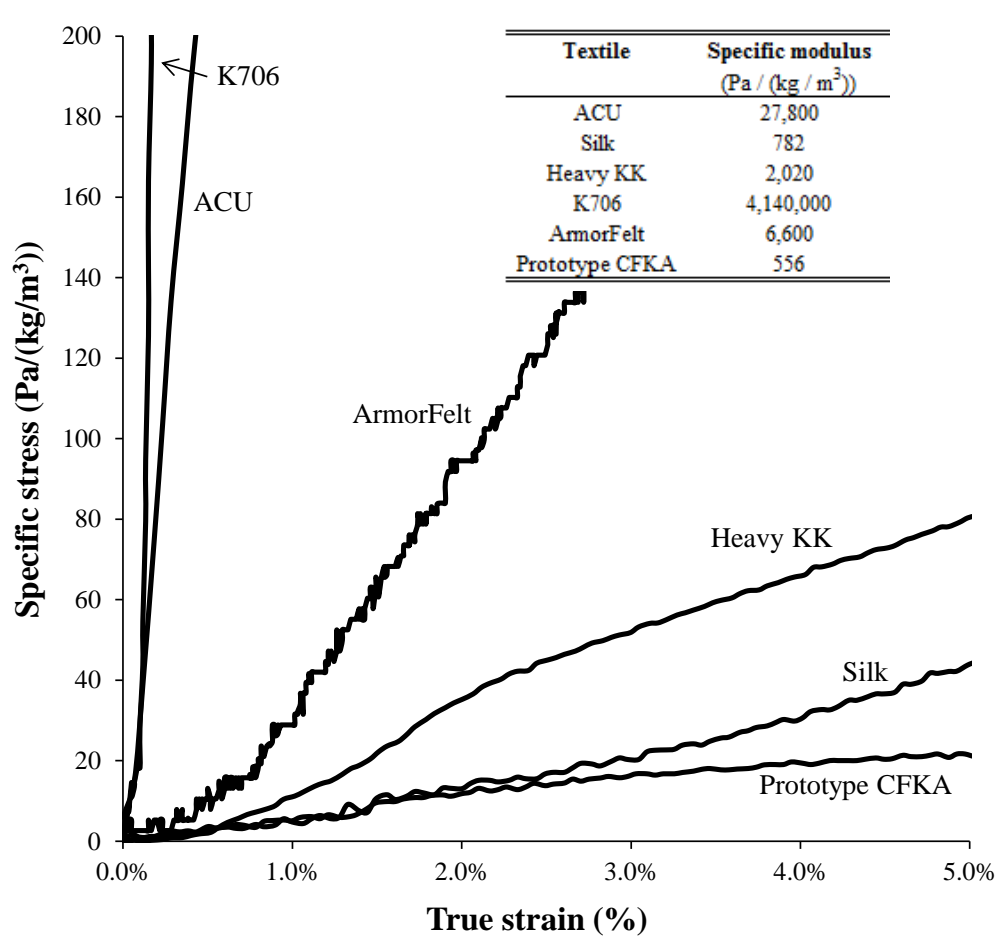

(b)

Figure 7: Tension testing results. (a) Load versus displacement, and (b) specific stress versus true strain, with inset table of estimated specific modulus values for each sample. 
Dwivdei et. al, "Low Velocity Ballistic Behavior... Knit Aramid"

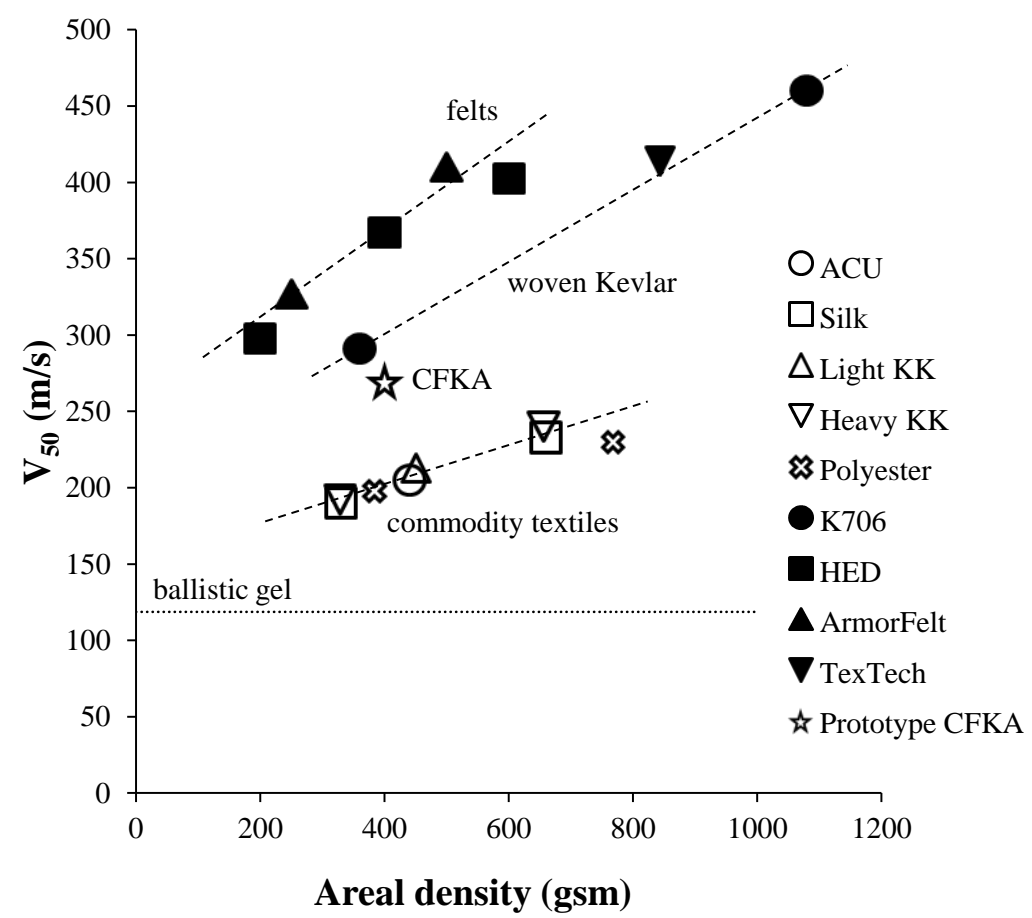

Figure 8: Ballistic performance of baseline materials and Prototype CFKA. Dashed lines are guides to the eye. 
Dwivdei et. al, "Low Velocity Ballistic Behavior... Knit Aramid"
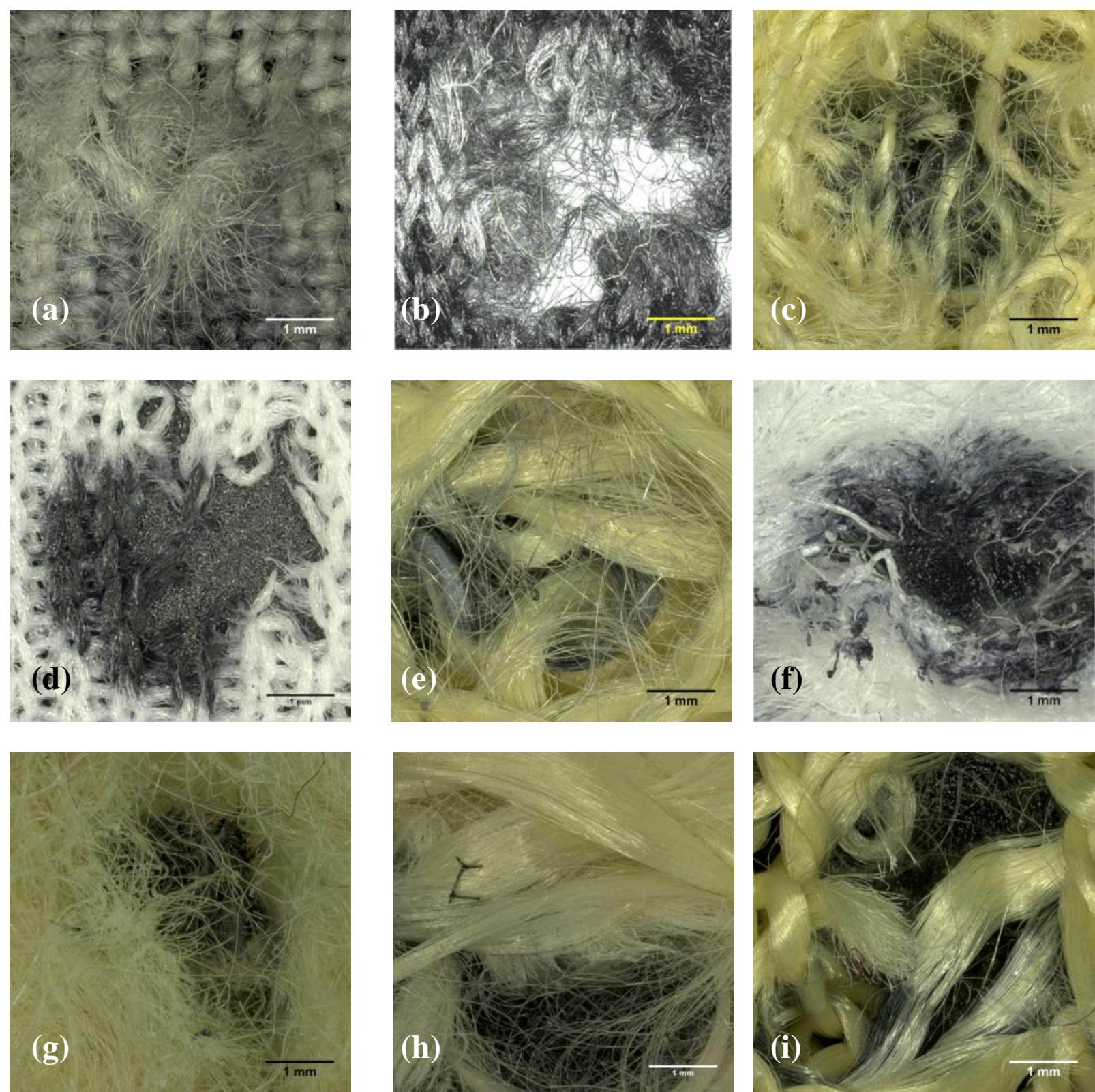

Figure 9: Micrographs of failure regions. (a) ACU, (b) Silk, (c) Light KK, (d) Polyester, (e) K706, (f) HED, (g) ArmorFelt, (h) TexTech, and (i) Prototype CFKA. (The blackness in the impact region is residual ink from marking the shot location prior to testing.) Heavy KK (not shown) is similar in appearance to Light $\mathrm{KK}$. 
Dwivdei et. al, "Low Velocity Ballistic Behavior... Knit Aramid"

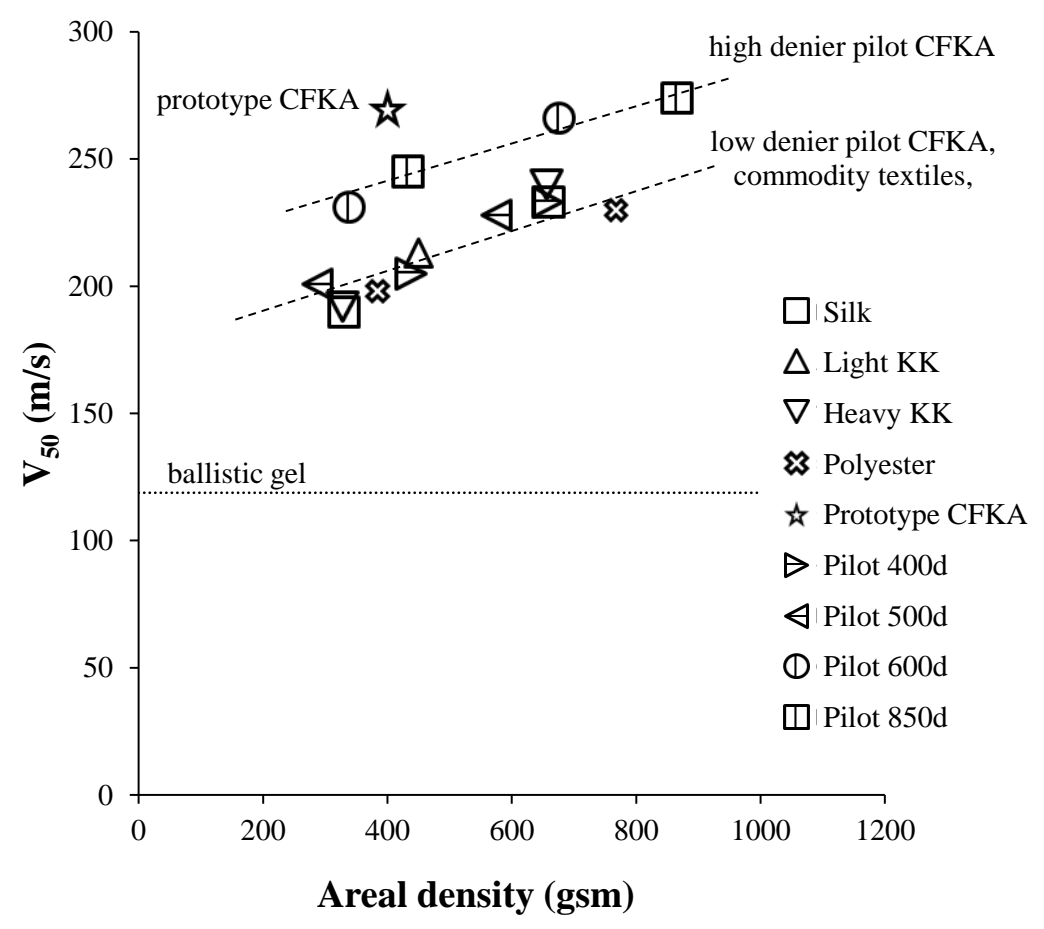

Figure 10: Ballistic performance of pilot CFKA materials. Lines are guides to the eye. 
Dwivdei et. al, "Low Velocity Ballistic Behavior... Knit Aramid"

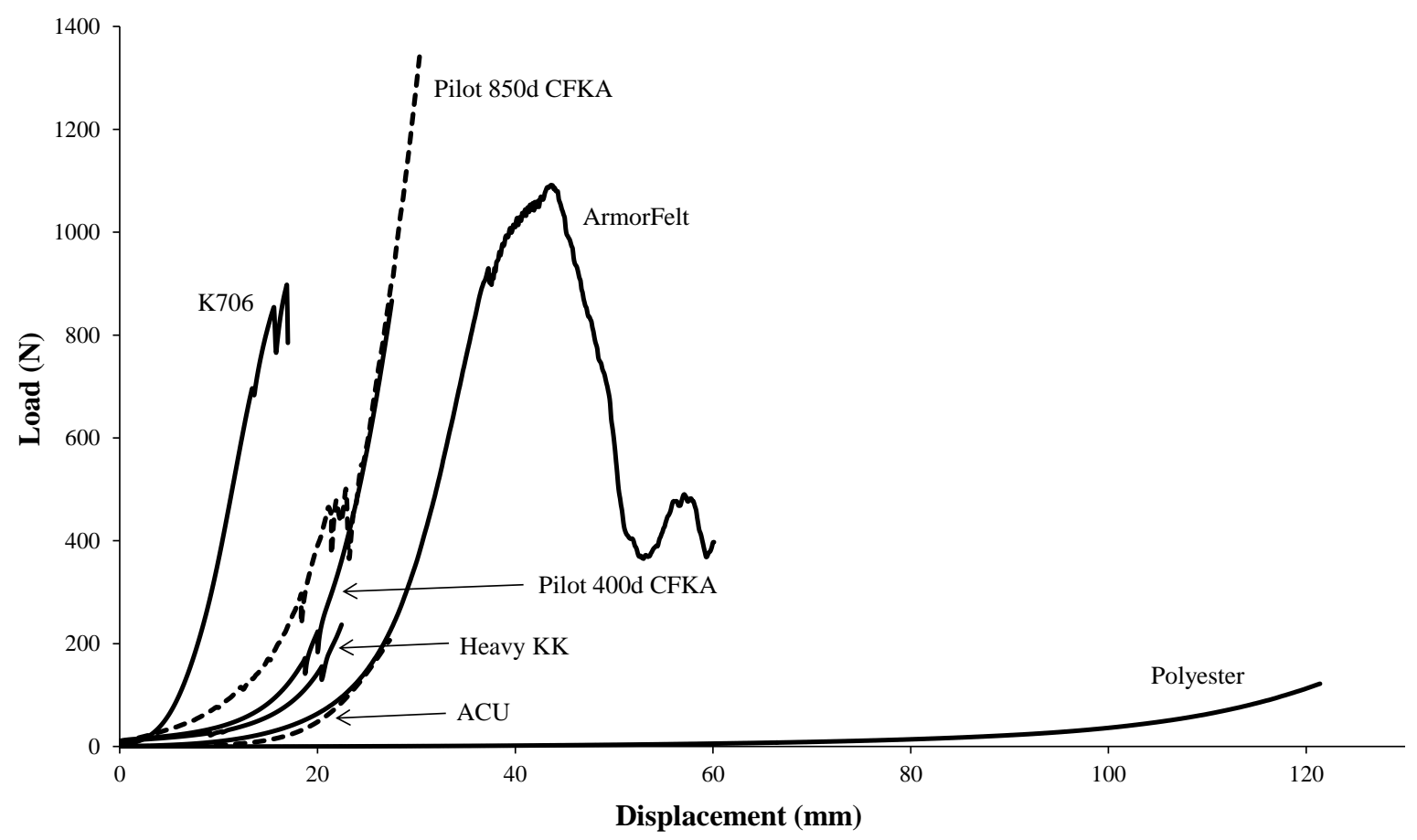

Figure 11: Force curves for quasistatic puncture experiments on single-layer targets. For all samples not including ArmorFelt, data is shown up until the point of failure, after which the load drops rapidly suddenly to a low value. For ArmorFelt, failure is more gradual. The load noise prior to failure for Heavy KK, K706, 400d SJ, and 850d SJ samples is due to multiple premature high speed camera triggering events, resulting in a pause in the experiment and subsequent stress relaxation while the triggers were reset. 
Dwivdei et. al, "Low Velocity Ballistic Behavior... Knit Aramid"

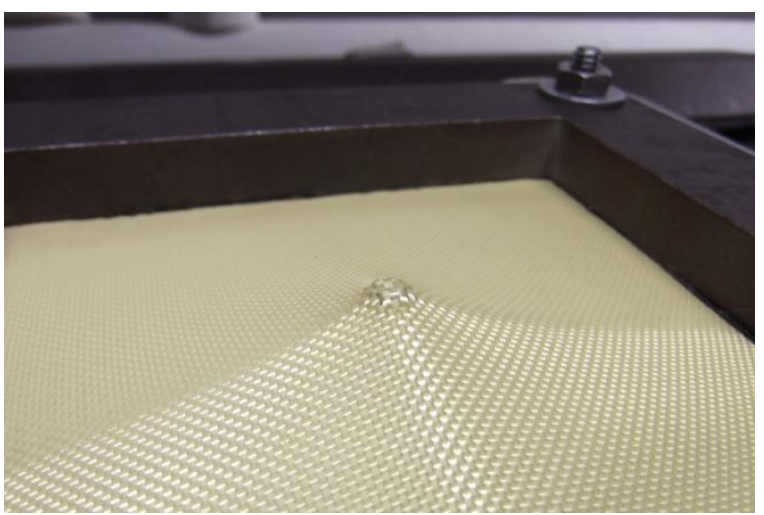

(a)


(b)



(c)

Figure 12: Comparison of fabrics near failure during quasistatic puncture testing. (a) K706, (b) ArmorFelt, and (c) polyester. 

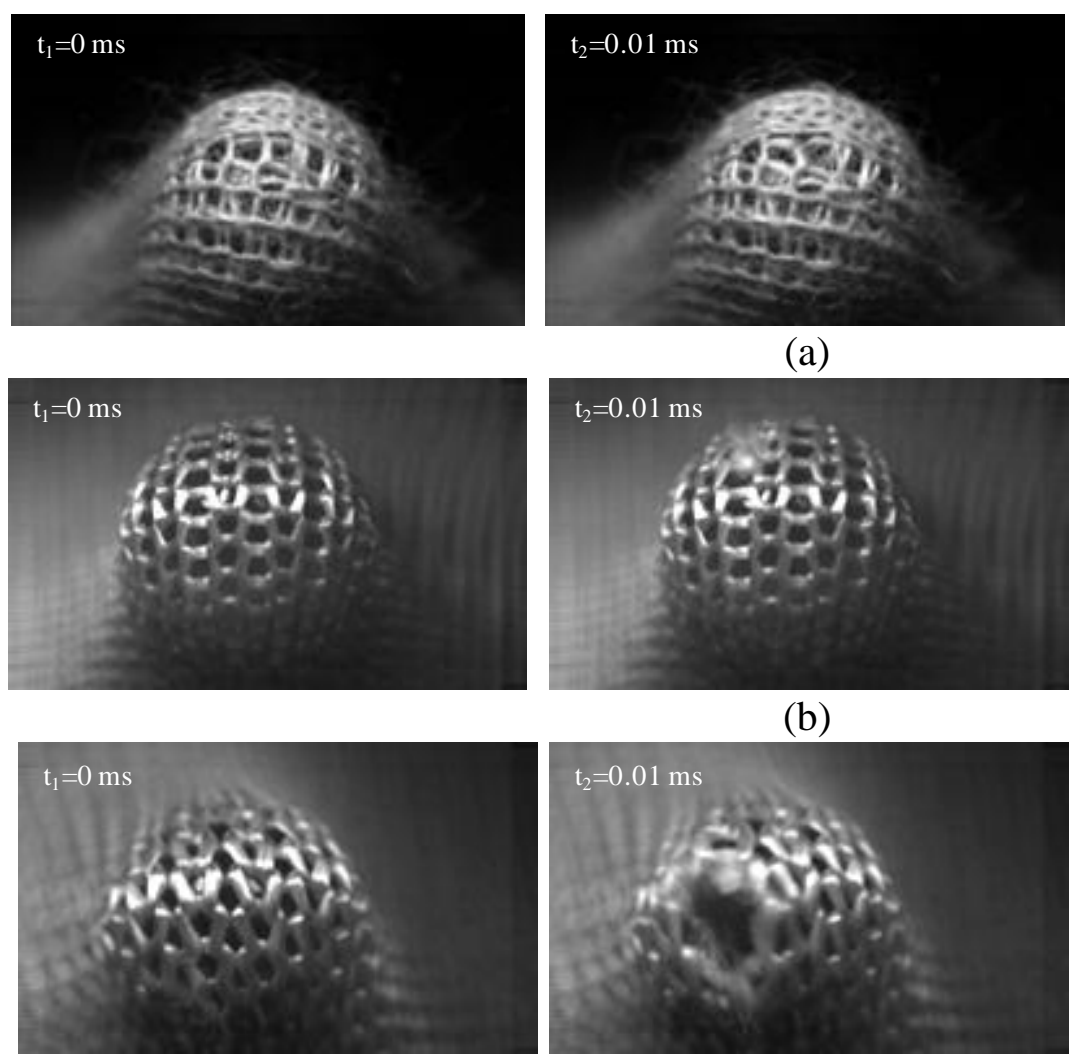

(c)

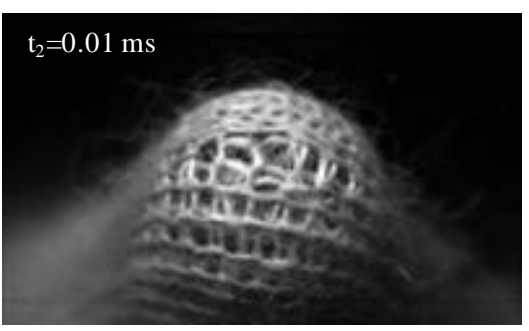

(a)

(b)
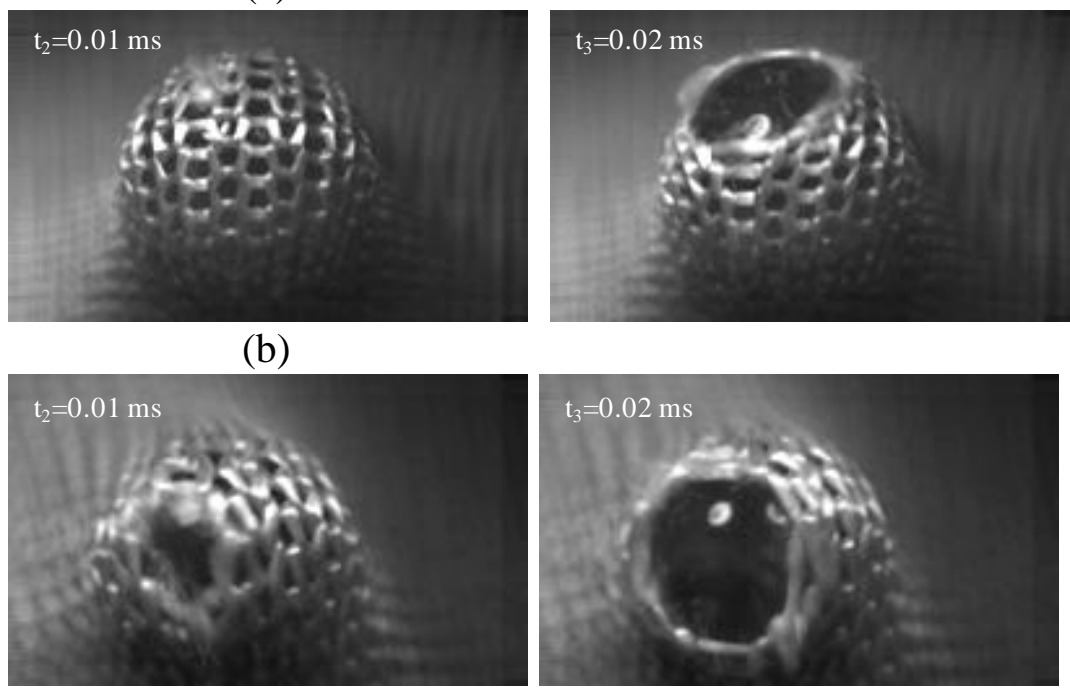

Figure 13: High speed video images during quasistatic puncture testing for (a) Heavy KK, (b) Pilot 400d CFKA, and (c) Pilot 850d CFKA knits. 
Dwivdei et. al, "Low Velocity Ballistic Behavior... Knit Aramid"

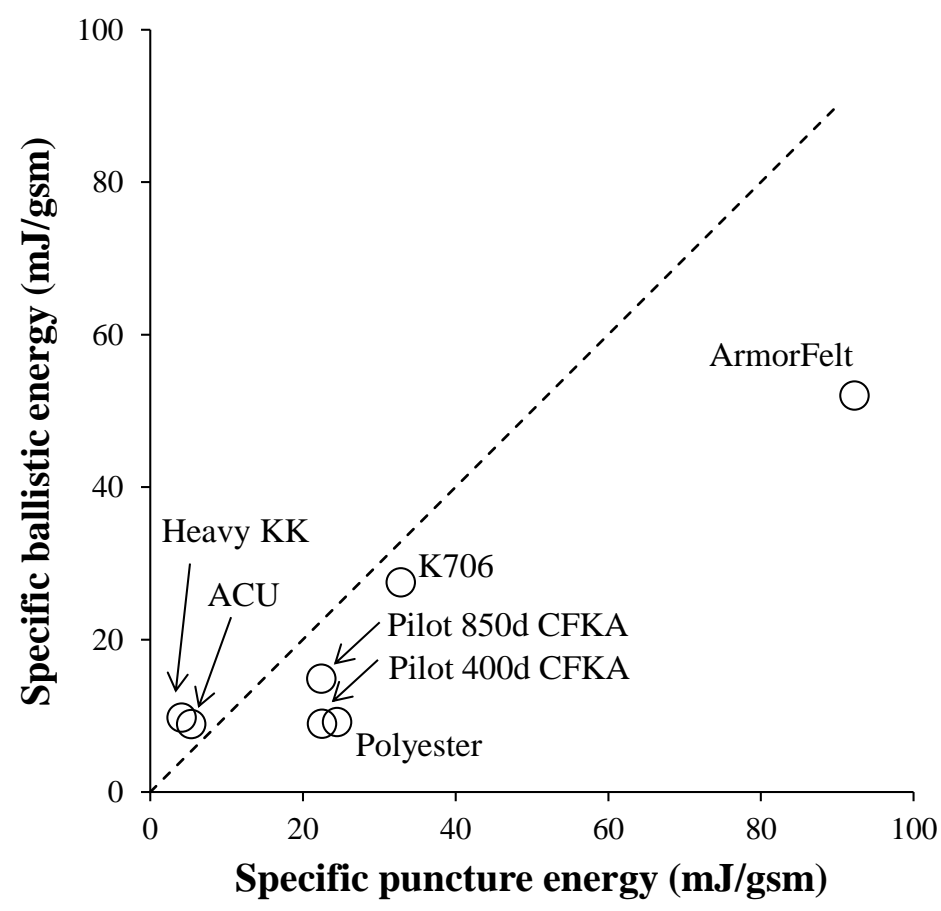

Figure 14: Specific ballistic energy versus specific puncture energy for select targets. Dashed line indicates trend for specific ballistic energy equal to specific puncture energy. 

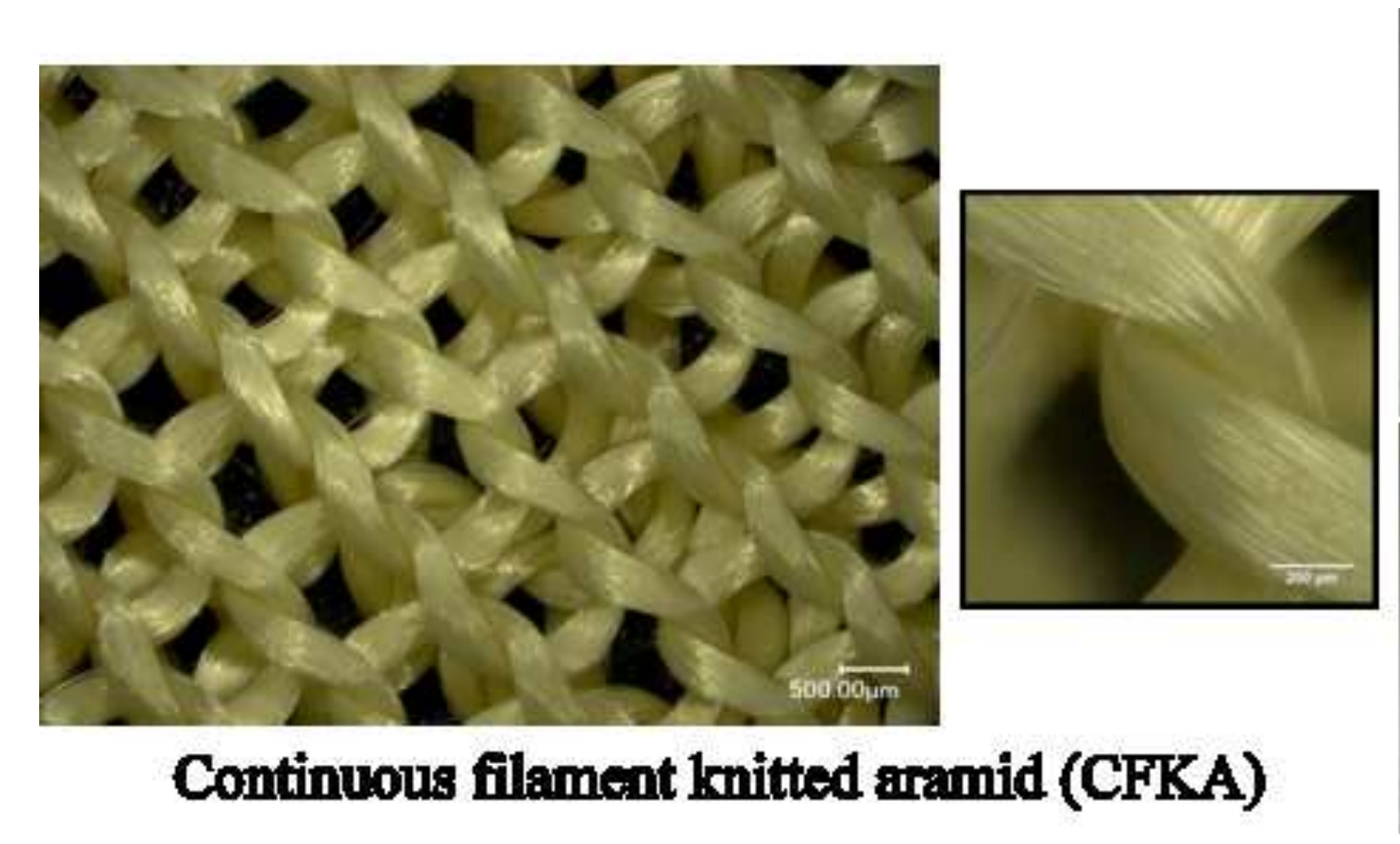

Continuous filament knitted aramid (CFKA)

\section{)}

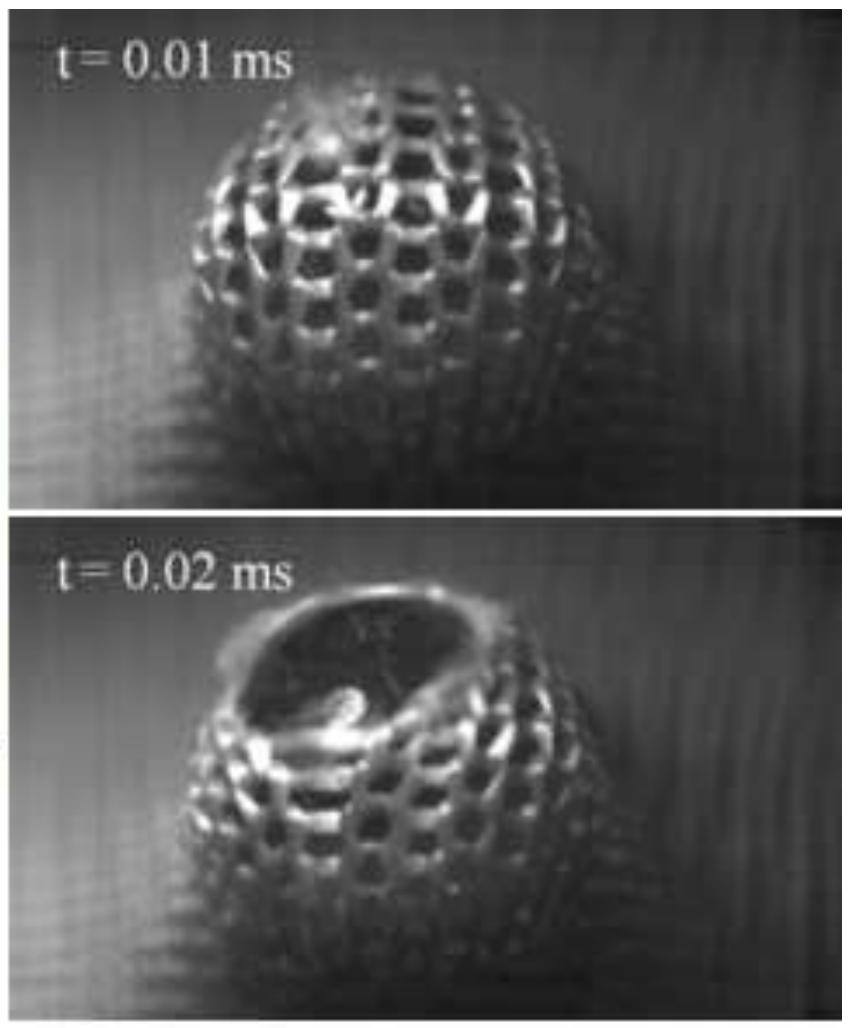

